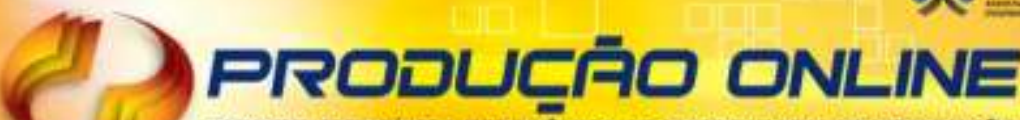 REVISTA CIENTIFICA ELETRONICA DE ENGENHARIA DE PRODUÇĀO ISSN 1676-1901
}

\section{AVALIAÇÃO ECONÔMICA DA APLICAÇÃO DA PRODUÇÃO MAIS LIMPA EM UMA ESTAÇÃO DE TRATAMENTO DE EFLUENTES: ESTỦDO DE CASO EM UMA EMPRESA METAL MECÂNICO}

\section{ECONOMIC EVALUATION OF THE APPLICATION OF THE CLEANER PRODUCTION IN AN EFFLUENT TREATMENT STATION: CASE STUDY IN A MECHANICAL METAL COMPANY}

\author{
Roberto Rodrigues Leite* E-mail: rodlei@bol.com.br \\ Geraldo Cardoso de Oliveira Neto* E-mail: geraldo.prod@gmail.com \\ *Universidade Nove de Julho (UNINOVE), São Paulo, SP
}

Resumo : Esse trabalho tem como objetivo demonstrar por meio da metodologia de estudo de caso, a avaliação econômica da aplicação da Produção Mais Limpa na Estação de Tratamento de Efluentes de uma pequena empresa brasileira do ramo metal mecânico, na qual o ganho econômico foi de $R \$$ $4.994,67$ por mês obtidos com um investimento de $R \$ 4.560,00$, demonstrando que a Produção Mais Limpa proporciona, com pouco investimento inicial, resultados econômicos positivos em curto prazo por meio do uso consciente dos recursos hídricos e atendendo a legislação ambiental local que trata de efluentes industriais, evidenciando que a Produção Mais Limpa é um instrumento que possibilitando obter ganhos econômicos por meio de ações direcionadas à minimização dos impactos causados ao meio ambiente pelos processos produtivos industriais.

Palavras-chave: Produção Mais Limpa. Estação de Tratamento de Efluentes. Avaliação Econômica.

Abstract: This study aims to demonstrate, through the case study methodology, the economic evaluation of the application of the Cleaner Production at the Effluent Treatment Station of a small Brazilian metal mechanic company, in which the economic gain was $R \$ 4,994,67$ per month obtained with an investment of $R \$ 4,560.00$, demonstrating that the Cleaner Production provides, with little initial investment, positive economic results in the short term through the conscious use of water resources and taking into account the local environmental legislation that treats of industrial effluents, showing that the Cleaner Production is an instrument that allows to obtain economic gains through actions directed to the minimization of the impacts caused to the environment by the industrial production processes.

Keywords: Cleaner Production. Effluent Treatment Station. Economic Evaluation.

\section{INTRODUÇÃO}

O crescimento das atividades industriais tem provocado problemas que antes não eram observados em termos ambientais. Como resultado de intenso desenvolvimento industrial os impactos ambientais têm evoluído, resultando em severa degradação ambiental, prejudicando o ecossistema (ROSENBLOOM, 2001; HOFFMAN, 2001). A busca pela produção mais eficiente e lucrativa vem gerando 
ganhos do ponto de vista econômico e social, porém, tem provocado a degradação nos ecossistemas, que somado ao aumento populacional e fatores climáticos, acaba limitando o acesso à água tratada, entre outras questões ambientais.

A possibilidade de incluir a preocupação ambiental ao desenvolvimento sustentável como estratégia organizacional por meio de práticas ecologicamente corretas, pode se tornar uma ação decisiva para a manutenção das organizações nas próximas décadas. Dessa maneira, inovações que visam a melhoria dos processos produtivos, a redução de custos e menor consumo de insumos e energia, tornam-se essenciais para a competitividade e rentabilidade organizacional.

As indústrias metalúrgicas consomem grande quantidade de água em seus processos produtivos e, consequentemente, gera vários tipos de resíduos e efluentes contaminantes para o meio ambiente, dessa maneira, precisam encontrar uma solução para este problema, que pode ir da conscientização e necessidade de pesquisa cientifica até uma legislação rígida. O principal objetivo é a redução dos impactos ao meio ambiente, porém, sem alterar as características produtivas das empresas (MOORS et al., 2005).

As pesquisas apontam que as indústrias estão adotando novas formas de atuação. Conforme Clemens, (2006) as indústrias estão utilizando a variável ambiental em suas estratégias, e segundo Halila, (2007) pelo fator coercitivo que aparece na forma de regulamentações, e conforme Jabbour, (2010) pelo fator econômico, que aparece na forma de oportunidades competitivas. Na procura por soluções que reduzam os problemas ambientais os gestores estão adotando ferramentas que ajudam as organizações a agirem de forma proativa sobre questões direcionadas à gestão dos recursos naturais (VAN BERKEL, 2000).

As indústrias são impactantes ao meio ambiente e precisam investir em um novo cenário, onde as questões ambientais sejam inseridas nos seus processos de fabricação sem prejuízo ao seu desenvolvimento, porém, conforme Silvestre e Silva Neto, (2014), as pequenas empresas (PEs) encontram grandes dificuldades econômicas para tais investimentos, em razão das poucas políticas de incentivo do governo e muita burocracia para financiamentos. Conforme Daquino et al., (2014) a principal limitação para a implementação da $\mathrm{P}+\mathrm{L}$ nas $\mathrm{PEs}$ está relacionada à falta de capital para investimento.

A poluição das águas é assunto cada vez mais preocupante e urgente de 
solução, principalmente pelas atuais condições climáticas que vêm agravando muito o problema, reduzindo a níveis preocupantes os mananciais, tornando a questão do uso da água ainda mais relevante e preocupante. Para Vieira e Amaral, 2016 o tratamento da água se torna uma necessidade para as empresas, e também um problema, em razão do seu custo elevado. Nesse contexto, surge a Produção Mais Limpa $(\mathrm{P}+\mathrm{L})$, que segundo a Organização das Nações Unidas para 0 Desenvolvimento Industrial e a United Nations Environmental Programme UNIDO/UNEP (2017) promove uma estratégica econômica, ambiental e tecnológica associada aos processos e produtos aumentando a eficiência no uso de matériasprimas, água e energia, pela não geração, diminuição ou reciclagem de resíduos gerados nos setores produtivos, e conforme Van Hoff e Lion (2013) aplica uma abordagem preventiva permitindo que a indústria atue de modo social e ambiental responsável, possibilitando ganhos ambientais e econômicos.

Os problemas ambientais são complexos, e em grande parte, atribuídos aos processos industriais, porém, as empresas em sua grande maioria, dispõem de poucos recursos e incentivos financeiros, assim, as organizações podem minimizar o seu impacto ao meio ambiente por meio da P+L. A falta de incentivos resulta no desinteresse das empresas por ações direcionadas à preservação ambiental, por entenderem que tais ações não geram retorno econômico (VIEIRA e AMARAL, 2016).

Nos artigos pesquisados não foram identificadas metodologias quantitativas para avaliação econômica da implantação da $\mathrm{P}+\mathrm{L}$ em ETEs, também não foram identificados artigos que apresentam cálculo de retorno de investimentos (ROI) pela aquisição de equipamentos para o reuso da água. Segundo Eder, (2003): Silvestre e Silva Neto, (2014) se as empresas pudessem determinar o retorno do investimento, atingindo principalmente valores atrativos, estariam mais dispostas a aprovar a adoção do $\mathrm{P}+\mathrm{L}$. Dessa maneira ficam evidenciadas duas lacunas de pesquisa que consistem na ausência de metodologias quantitativas para avaliação econômica da implantação de $P+L$ e cálculo ROI.

Com base nas lacunas identificadas, este estudo propõe responder as seguintes perguntas de pesquisa: 1) O ganho econômico permite que as empresas do setor metal mecânico adotem ações de $P+L$ em seus processos produtivos? 2) $A$ identificação do tempo de retorno do investimento por meio do calculo ROI motiva as 
PEs a adotarem a $P+L$ ?

Para responder estas questões de pesquisa foi realizado um estudo de caso exploratório em uma pequena empresa do segmento metal mecânico por meio da aplicação de ações de $\mathrm{P}+\mathrm{L}$ em sua ETE. Os instrumentos de pesquisa utilizados foram entrevistas semi estruturadas, observações locais e registros em arquivos. A análise dessas fontes tornou possível a obter os resultados econômicos e a avaliação do tempo de retorno do investimento.

Este artigo está organizado em seis seções, após a introdução é apresentada uma revisão sistemática da literatura sobre Produção Mais Limpa, Pequenas Empresas, Produção Mais Limpa na Pequena Empresa Metal Mecânica, Barreira Econômica da P+L e Legislação Ambiental, a Metodologia, Estudo de Caso, discussão e conclusões.

\section{REVISÃO DA LITERATURA}

\subsection{Produção Mais Limpa $(P+L)$}

Criada pela United Nations Environmental Programme (UNEP), a expressão Produção Mais Limpa surgiu em 1989 como uma estratégia contínua de prevenção ambiental a processos, produtos e serviços, aumento da eficiência da produção e reduzindo os riscos para o homem e o meio ambiente (UNEP, 2004). Conforme a Organização das Nações Unidas para o Desenvolvimento Industrial, UNIDO (2002) a $\mathrm{P}+\mathrm{L}$ é uma estratégia preventiva aplicada a todo ciclo de produção para aumentar a produtividade, assegurando o uso mais eficiente de matéria-prima, energia e água. A $\mathrm{P}+\mathrm{L}$ promove um melhor desempenho ambiental pela redução das fontes de desperdícios e emissão, reduzindo o impacto ambiental por todo o ciclo de vida do produto (UNEP, 2004). Além do aumento da competitividade e produtividade industrial, ela integra os processos e produtos aumentando a eficiência no uso de matérias-primas, água e energia, por meio da não geração, minimização ou reciclagem dos resíduos e emissões geradas (CNTL, 2003).

No Brasil, o Centro Nacional de Tecnologias Limpas (CNTL) promove o desenvolvimento sustentável, espalhando a filosofia de eco eficiência e $P+L$, para aumentar a competitividade, inovação, responsabilidade social e ambiental das 
organizações. Segundo (CNTL, 2017) o conceito de $P+L$ se refere a ações que permitem que uma empresa se qualifique como usuário eficiente das matériasprimas e energia, aumentando a produtividade e competitividade, melhorando o desempenho organizacional. Segundo Kliopova e Staniskis, (2006); Hicks e Dietmar, (2007) um programa de $\mathrm{P}+\mathrm{L}$ reduz resíduos sistêmicos e emissões, melhorando a qualidade dos produtos. A falta de preocupação com a prevenção da poluição $\mathrm{e}$ meio ambiente pela sociedade é um fator que acaba interferindo na percepção da necessidade das empresas em adotar práticas de $P+L$ (ZHANG, 2000).

A $\mathrm{P}+\mathrm{L}$ aprimora os processos, produtos e serviços, sendo um caminho positivo para as empresas prevenirem seus impactos ambientais, caminhando na busca da sustentabilidade (GAJDZIK, 2009). A prática da $P+L$ proporciona às empresas maior competitividade devido à economia que se alcança, bem como, a valorização da sua marca pela associação ao respeito pelo meio ambiente (PNUMA, 2017).

A estratégia da $\mathrm{P}+\mathrm{L}$ visa melhoria do comportamento ambiental das organizações, mais especificamente, sobre a redução dos custos de produção e o aumento da eficiência e da competitividade (VALLE, 1995). Ela tem o objetivo de melhorar as condições de saúde e segurança dos colaboradores, melhorar a imagem da empresa no mercado, resultando no aumento do nível de satisfação dos clientes (MEDEIROS et al., 2007).

A P $+\mathrm{L}$ conforme Giannetti e Almeida (2006) pode ser aplicada pelas empresas sem restrições, promovendo benefícios econômicos pela da redução dos custos operacionais e diminuição dos impactos ambientais, e segundo Radovic et al. (2009) pela otimização no uso de recursos e diminuição dos desperdícios, e conforme Lopes Silva et al. (2013) promove também benefícios sociais pela conscientização ambiental dos funcionários. A P+L admite diversos níveis de aplicação, desde o simples ato de refletir sobre as possibilidades de melhoria de seus processos, até a efetiva implantação de um programa de $\mathrm{P}+\mathrm{L}$ (CETESB, 2017). A P+L prioriza os esforços dentro de cada processo isolado, colocando a reciclagem externa entre as últimas opções (GIANNETTI e ALMEIDA 2006). O objetivo da P+L é identificar as fontes de geração de resíduos e suas causas, e na aplicação de soluções para eliminá-las, resultando em benefícios econômicos e ambientais em curto prazo (VAN BERKEL et al., 1997). 
A $P+L$ é um instrumento que pode ajudar de forma preventiva as empresas, possibilitando um melhor resultado em termos de aproveitamento das matérias primas e energia. A P+L minimiza as perdas no processo de fabricação e reduz a geração de resíduos e emissões de uma forma economicamente viável, possibilitando obter ganhos econômicos e ambientais (CNTL, 2017).

A adoção de boas práticas ambientais pelas empresas, conforme Worthington e Patton (2005) ajuda a melhorar o desempenho nos negócios, criando o chamado duplo dividendo do comportamento ambiental, o que segundo Studer; Welford e Hills (2006) estimula as empresas na buscar vantagens competitivas. Conforme Giannetti et al.,(2008) a $\mathrm{P}+\mathrm{L}$ é uma das principais variáveis do desenvolvimento sustentável e segundo Duarte et al., (2005) é reconhecida como um importante instrumento para operacionalização dos conceitos de gestão ambiental. Dessa maneira a $P+L$ cria uma maior conscientização entre as pessoas trazendo uma nova visão sobre os ganhos alcançados para o meio ambiente e para a sociedade (VAN BERKEL, 2007).

A P+L propõe a substituição do sistema "fim de tubo" de tratamento dos descartes por um sistema que abrange os processos de produção e procedimentos de gestão, o que segundo Petroesc e Moraru (2011) minimiza a utilização de recursos gerando menos resíduos, tendo seu inicio desde o projeto do produto até a disposição final ou a sua reutilização.

\subsection{Pequenas Empresas}

A importância das PEs vem aumentando com o passar do tempo e a literatura vem abordando o seu importante papel em todas as economias. As PEs são relevantes no contexto sócio econômico e poderoso fator de promoção social, base de estabilidade política e grande força no desenvolvimento por sua capacidade de gerar empregos (LEONARDOS, 1984). As PEs se caracterizam pela estrutura organizacional simples, pouca burocracia, poucos recursos humanos e financeiros, pouca variedade de produtos, flexibilidade e adaptabilidade às mudanças (DEITOS, 2002).

No Brasil, segundo as Leis Federais, a classificação do tipo de empresa se dá de acordo com o tamanho da receita bruta durante o ano-calendário. O Serviço 
Brasileiro de Apoio às Pequenas e Médias Empresas (SEBRAE) as classifica pelo número de colaboradores (pessoas ocupadas), conforme apresentado no Quadro 1.

Quadro 1 - Classificação das empresas

\begin{tabular}{|c|c|c|}
\hline \multirow[t]{2}{*}{ PORTE } & \multicolumn{2}{|c|}{ SETORES } \\
\hline & INDÚSTRIA & COMÉRCIO E SERVIÇOS \\
\hline Micro Empresa & até 19 pessoas ocupadas & até 09 pessoas ocupadas \\
\hline Pequena Empresa & de 20 a 99 pessoas ocupadas & de 10 a 49 pessoas ocupadas \\
\hline Média Empresa & de 100 a 499 pessoas ocupadas & de 50 a 99 pessoas ocupadas \\
\hline Grande Empresa & 500 pessoas ou mais ocupadas & 100 pessoas ocupadas ou mais \\
\hline
\end{tabular}

Fonte: SEBRAE (2005)

No setor industrial, as micro empresas (ME) contam com até 19 pessoas ocupadas, as pequenas empresas (PE) com até 99 pessoas ocupadas, as médias empresas (ME) com até 499 pessoas ocupadas, e as grandes empresas com mais de 500 pessoas ocupadas. As PEs são responsáveis por grande parte dos empregos no Brasil, atuando principalmente no comércio e serviços com $80 \%$ do total de PEs, e outros 14\% na indústria (SEBRAE, 2017). Elas têm grande representatividade no total de empresas registradas no Brasil, sendo responsáveis por aproximadamente $20 \%$ do produto interno bruto (PIB) brasileiro.

As PEs respondem com grande agilidade às mudanças impostas pelo mercado, se adaptando rapidamente às oportunidades que surgem no mercado e na economia, o que contribui para seu crescimento econômico (DELOITTE, 2011).

\subsection{Produção Mais Limpa na Pequena Empresa Metal Mecânica}

As PEs metal mecânicas ignoram os fatores ambientais pela necessidade de produção em curto prazo, direcionando sua atenção conforme Oliveira e Alves, (2007) aos processos produtivos em razão da pouca disponibilidade de recursos e segundo Silva et. al., (2015) pela necessidade de produção em curto prazo.

A opção de implantar a $\mathrm{P}+\mathrm{L}$ proporciona para as PEs metal mecânicas melhorias no seu desempenho ambiental e na qualidade de seus produtos com redução de custos, tornando-as mais competitivas (ALMEIDA et al., 2015). As PEs que superam a barreira econômica e implantam ações de $\mathrm{P}+\mathrm{L}$ em seus processos, 
segundo Klewitz e Hansen (2014) reduzem seus impactos ao meio ambiente expandindo sua responsabilidade ambiental e social. Para Almeida et al., (2015) é muito importante a expansão da responsabilidade ambiental e social das PEs metal mecânicas, pois, sua sobrevivência requer a integração dos aspectos ambientais, econômicos e sociais.

De acordo com Oliveira e Alves (2007) e Severo et al., (2015) as PEs metal mecânicas não possuem profissionais capacitados tecnicamente para promover inovações em seus produtos e processos com foco na preservação do meio ambiente, fator que para Sissino e Moreira, 2005 e Severo e Olea, 2010 é importante para identificar as barreiras que dificultam a implantação da $\mathrm{P}+\mathrm{L}$, aspecto que para Klewitz e Hansen, (2014) viabiliza a busca das PEs metal mecânicas por alternativas e soluções sustentáveis relacionadas aos seus processos e produtos.

Resultados econômicos com a $\mathrm{P}+\mathrm{L}$ podem ser obtidos de duas maneiras pelas PEs metal mecânicas, quando não há investimentos iniciais ocorrendo a principio uma redução dos custos pela simples adoção de ações, e quando há investimentos em novas tecnologias para melhoria no processo de fabricação, resultando na redução dos custos, o que possibilita a recuperação dos investimentos (CNTL, 2003). Conforme Shi et al., (2008) o principal fator para a decisão de implantação da $\mathrm{P}+\mathrm{L}$ em PEs está na identificação e superação das barreiras de forma economicamente viável. Entende-se portanto, ser a avaliação econômica o fator determinante para a decisão de implantação da $\mathrm{P}+\mathrm{L}$, pois, conforme Zhang et al., (2009) os empresários das PEs somente se engajam em projetos ambientais se tais projetos proporcionarem algum retorno econômico para sua empresa.

\subsection{Barreira econômica da P+L}

As pesquisas que tratam das barreiras da $\mathrm{P}+\mathrm{L}$ apontam para o fator econômico, que está relacionada à falta de capital para investimentos (SILVESTRE e SILVA NETO, 2014). Tal fator afeta o direcionamento dos poucos recursos que as empresas dispõe, que geralmente são aplicados para o aumento da produção sem observar seus resultados ambientais (DAQUINO et al., 2014). 
As empresas do setor metal mecânico encontram dificuldades relacionadas a fatores financeiros, econômicos, entre outros, o que dificulta a implantação de ações de P+L. Para superar os obstáculos encontrados (BAAS, 2007). Elas também se defrontam problemas latentes que afetam seu crescimento e sobrevivência, por possuírem máquina, equipamentos e ferramentas obsoletos em razão de não possuírem condições econômicas para investir em tecnologias limpas e mão de obra especializada (CAMARGOS et al., 2010). A falta de investimentos em novas tecnologias segundo Siaminnwe et al., (2005) resulta em despejo de efluentes contaminados e disposição de resíduos em lixo comum, sendo necessário o tratamento "fim de tubo", o que conforme Oura e Souza (2007) é uma técnica considerada apenas reativa para solução de impactos ambientais.

As empresas enfrentam, também, dificuldades relacionadas ao elevado custo de capital associado ao risco do negócio. As instituições financeiras aplicam taxas de juros mais elevadas nos empréstimos, com exigências e condições inibidoras dificultando o acesso ao crédito, tanto de curto quanto de longo prazo (GONÇALVES et al.,2007). Outra dificuldade está na busca de informações e acesso a financiamento do governo e políticas de incentivo fiscal (SILVESTRE e SILVA NETO, 2014). As PEs também encontram dificuldades em obter melhores preços e vantagens na compra de matérias primas e componentes, entre outros, além dos aspectos que dizem respeito a fatores como falta de capital de giro, encargos e impostos elevados (BALESTRIN e VARGAS, 2004; CAMARGOS et al., 2010).

Benefícios econômicos podem ser alcançados pelas empresas com a $P+L$, mas dependem da disponibilidade de fundos e regulamentações. Os ganhos alcançados podem ser considerados como um instrumento alternativo para que as empresas adotarem iniciativas de P+L (ZHANG et al., 2013).

Portanto, uma oportunidade para superar o obstáculo econômico à adoção da $P+L$ pelas empresas é aumentar a conscientização de que a implementação da $P+L$ pode resultar em ganhos econômicos que justifiquem sua execução (SILVESTRE e SILVA, 2014). Com um bom retorno do investimento, as empresas podem implantar a $\mathrm{P}+\mathrm{L}$ superando as dificuldades existentes (ABDULRAHMAN et al., 2015). 


\subsection{Legislação Ambiental no Brasil}

Devido aos diferentes tipos de poluentes lançados nos corpos receptores são necessários diversos parâmetros de controle analítico, sendo normalmente utilizados os de natureza física, química e biológica. É necessário também, associar a medição de vazão com a coleta de amostras, análises laboratoriais, sua interpretação e comparação com a legislação ambiental. As análises das amostras dos efluentes brutos servem para verificar a sua variabilidade, quantificar a carga poluidora, encontrar o processo adequado de tratamento e dimensionar os sistemas para avaliar as sua eficiência.

Para determinar carga poluidora dos efluentes industriais, é necessário conhecer previamente o processo industrial para definir adequadamente o programa de amostragem. As informações necessárias são: Lista de matérias prima, em especial aquelas que de alguma forma são transferidas para os efluentes; fluxo do processo de fabricação indicando os pontos de geração de efluentes; identificar os pontos de lançamento de efluentes; elaborar uma forma de medição de efluentes e instalá-lo.

No regulamento da Lei do Estado de São Paulo 997 de 31.05.76, aprovado pelo Decreto 8468 de 08.09.76 e também da Resolução Federal CONAMA (Conselho Nacional de Meio Ambiente) no 357, constam os parâmetros e limites a serem obedecidos, tanto para efluentes líquidos (padrão de emissão), como para corpos hídricos receptores (padrão de qualidade). No Estado de São Paulo, desde 1976, está em vigor o decreto 8468/76, que regulamenta a Lei 997/76 e suas posteriores modificações, o qual, na seção 2 , trata dos padrões de emissão dos poluentes apresentando os parâmetros para liberação de efluentes em corpos receptores ou rios (artigo 18) ou para a rede de esgoto (artigo 19 A). A aplicação da lei e das normas compete à Companhia Estadual de Tecnologia de Saneamento Básico e de Defesa do Meio Ambiente (CETESB), bem como a fiscalização das atividades e licenciamento ambiental das empresas. Nos dispositivos legais estão estabelecidos os limites máximos de poluentes que podem estar presente no efluente para que o descarte seja considerado regular.

Em nível federal, foi publicada a resolução no 430, de 13 de maio de 2011, que dispõe sobre a classificação dos corpos de água e diretrizes ambientais para o seu 
enquadramento, e estabelece as condições e padrões de lançamento de efluentes. Esta resolução complementa e altera parcialmente a de no 357, de 17 de março de 2005, do Conselho Nacional do Meio Ambiente (CONAMA). Os comitês de bacia devem aplicar essa legislação definindo a classe dos corpos hídricos presentes na bacia, e o licenciamento ambiental para o descarte de efluentes pelas indústrias deve ser feito considerando essas classes. Portanto, tanto os padrões estabelecidos pelas normais estaduais quanto federais devem ser observados, valendo sempre aquele que for o mais restritivo.

O Quadro 2 apresenta a legislação para lançamentos de efluentes em corpos d'água e em sistemas públicos de esgotos de acordo com a legislação federal para o Estado de São Paulo.

Quadro2 - Legislação para lançamentos de efluentes

\begin{tabular}{|c|c|c|}
\hline \multirow{2}{*}{ LANÇAMENTIS } & \multicolumn{2}{|c|}{ LEGISLAÇ $\widetilde{A} \square$} \\
\hline & ESTADU DE SäL PAULD & FEDERAL \\
\hline EM CURPQS D'ÁGUA & Artigo 18 (1) & Artigo 34 (2) \\
\hline $\begin{array}{l}\text { EM SISTEMAS PUBLICDS } \\
\text { DE ESGUTUS (3) }\end{array}$ & Artlgo 19-A (4) & ---- \\
\hline
\end{tabular}

Fonte: CETESB (2017)

O Artigo 19 A" do decreto 8468 de 1976 conforme previsto no parágrafo $4^{\circ}$ para descarte em rede pública estabelece os seguintes requisitos: $\mathrm{pH}$ entre 6,0 e 10 (inteiros); Temperatura inferior a $40^{\circ} \mathrm{C}$ (Celsius); Materiais sedimentares até $20 \mathrm{ml} / \mathrm{l}$ em teste de uma hora em cone Imhof; Ausência de graxas e óleo, concentração de 150 mg/l de substâncias solúveis em hexano; Ausência de substâncias explosivas ou inflamáveis; Ausência de substâncias que causem entupimento das canalizações; Ausência de qualquer substância em concentrações tóxicas a processos biológicos.

A fórmula de cálculo, conforme CETESB (2017), que fixa a toxicidade permissível para efluentes líquidos (Resolução SMA n $3 / 00$ ) é apresentada no Quadro 3: 
Quadro 3 - Formula de cálculo de toxidade

D.E.R. $\leq \frac{C_{50} \text { ou } C_{50}}{100}$ ou D.E.R. $\leq \frac{C E N Q}{10}$
aNDE:
D.E.R. $=\frac{\text { Vazăo Médla de Efluente } \times 100}{\text { Vazão Média do Efluente }+Q_{7,10} \text { do Corpo Receptor }}$

Fonte: CETESB (2017)

Os itens que compõe o cálculo que fixa a toxidade permissível para efluentes líquidos são os seguintes:

- D.E.R = Diluição do Efluente no Corpo Receptor, em \%;

- CE50 = Concentração do efluente que causa efeito agudo a $50 \%$ dos organismos aquáticos, em um determinado período de tempo, em \%;

- CL50 = Concentração do efluente que causa efeito agudo (letalidade) a 50\% dos organismos aquáticos, em um determinado período de tempo, em \%;

- CENO = Concentração do efluente que não causa efeito crônico observável, \%.

\section{METODOLOGIA}

Inicialmente foi realizada uma revisão da literatura conforme orienta Santos e Kobashi, (2009) sobre $P+L$, barreiras econômicas da $P+L$ e legislação ambiental no Brasil. Posteriormente foi feito uma analise dos resultados econômicos na implantação da $\mathrm{P}+\mathrm{L}$ em uma ETE de uma empresa do setor metal mecânico, por meio de um estudo de caso de origem exploratória, que segundo Yin (2015) procura identificar as várias manifestações do problema e descrevê-lo de várias formas e pontos de vista. Caracteriza-se também como quantitativo, pois tem a preocupação de analisar e interpretar amostras amplas e informações numéricas (MARCONI e LAKATOS, 2005).

As fontes de evidências para realização deste estudo foram obtidas por meio de entrevistas semi estruturadas, coleta de dados documentais e observação local, gerando dados qualitativos e quantitativos (EISENHARDT, 1989). Conforme Yin (2015) as evidências para um estudo de caso podem vir de seis fontes distintas: 
documentos, registros em arquivo, entrevistas, observação direta, observação participante e artefatos físicos.

A entrevista foi realizada com o supervisor/gerente da produção, constituindo-se uma ferramenta importante para o desenvolvimento do trabalho (BRYMAN, 1995; COLLINS e HUSSEY, 2007). As observações foram realizadas no processo produtivo e a pesquisa documental utilizou os registros em arquivo fornecidos pela empresa complementando as informações da entrevista para o levantamento de dados qualitativos e quantitativos (BOGDAAN e BIKLEN, 1992).

Os cálculos dos ganhos econômicos obtidos com a implantação das ações de $\mathrm{P}+\mathrm{L}$ na ETE da empresa foram feitos observando-se os resultados econômicos anteriores e posteriores á implantação das ações, por meio de um estudo econômico realizado nos gastos com investimentos para o reaproveitamento da água no processo produtivo e na manutenção da ETE.

\section{ESTUDO DE CASO}

O estudo foi realizado em uma empresa localizada na cidade de São Paulo, Brasil. A empresa é classificada como de porte médio, atuando no setor secundário na fabricação de elementos de fixação pelo processo de conformação a frio em materiais como aço carbono, e alumínio. O fluxograma do processo de fabricação da empresa é apresentado na Figura 1.

Figura 1 - Visão geral do processo de fabricação

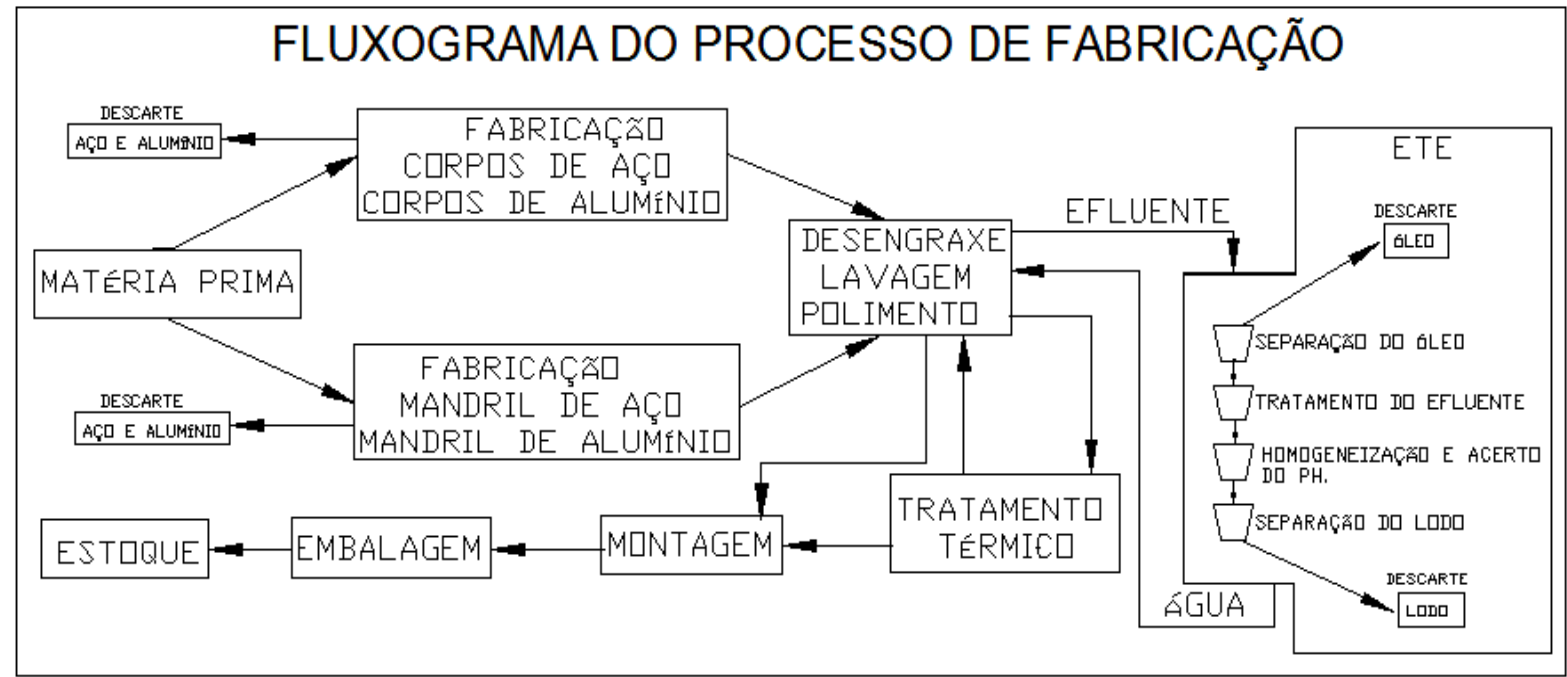

Fonte: Do autor 
O processo de fabricação se inicia nas etapas de fabricação de corpos e mandris, seguindo respectivamente os corpos para o desengraxe, lavagem, tratamento térmico e polimento, e os pinos para o polimento. Em seguida ambas as peças seguem para a montagem onde são unidas por meio de prensas, posteriormente testadas por amostragem, sendo em seguida embaladas e encaminhadas para o estoque e posterior expedição.

Em seu processo de fabricação, a empresa utiliza vários produtos químicos, como por exemplo, desengraxantes, abrilhantadores, óleos, etc. As etapas do processo que estão diretamente ligadas com a geração dos resíduos líquidos que são direcionados para a ETE são: fabricação de corpos e fabricação de mandril, tratamento térmico, polimento, lavagem e desengraxe, e descartado na rede pública. Para atender a legislação com o objetivo de atingir as concentrações em água dentro dos parâmetros de lançamento estabelecidos no "Artigo 19 A" do decreto 8468 de 1976, conforme previsto no parágrafo $4^{\circ}$ para descarte em rede pública, a empresa implantou uma ETE.

O fluxo do tratamento do efluente na ETE da empresa para descarte é apresentado na figura 2 :

Figura 2 - Fluxograma da Estação de Tratamento de Efluentes para descarte da água

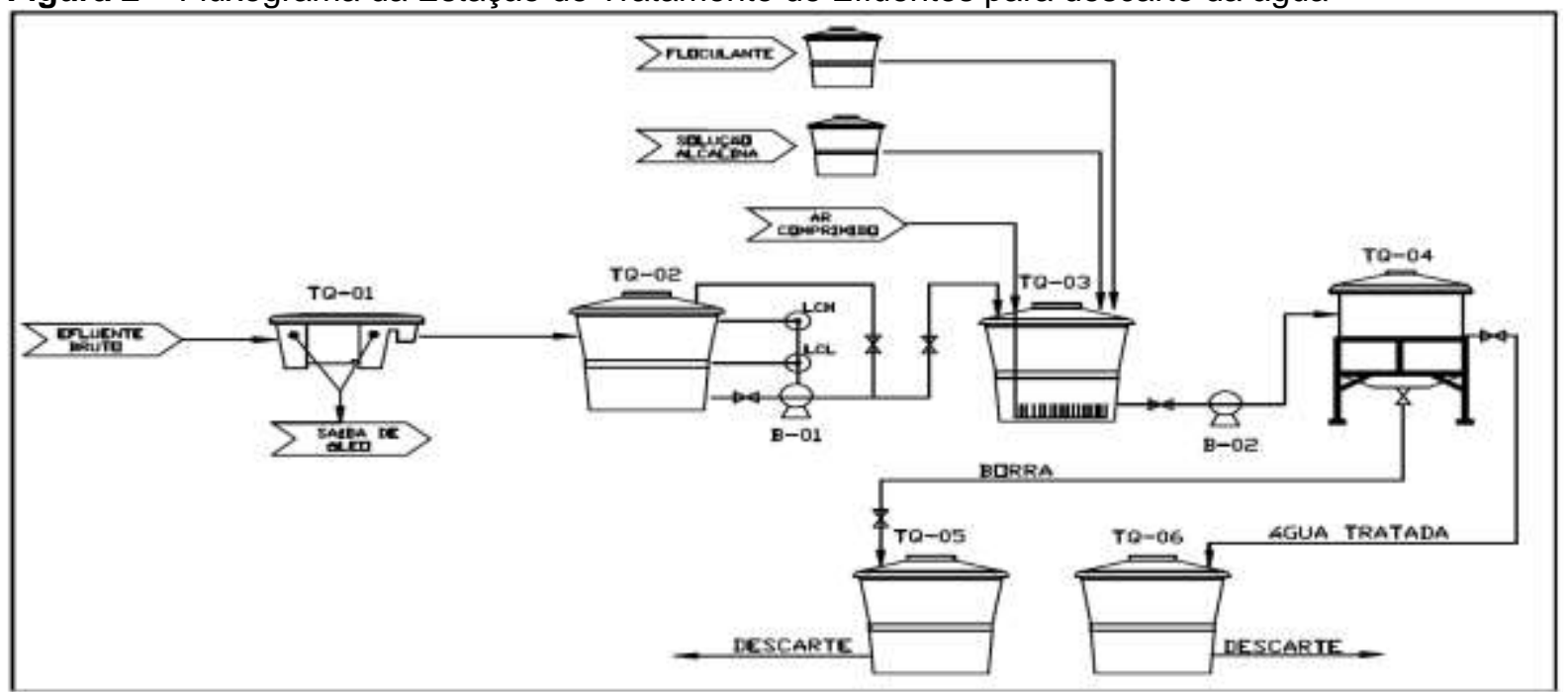

Fonte: Do autor

O processo de tratamento tem inicio no recebimento da água utilizada no processo de produção em caixa de gradeamento separadora de óleo insolúvel e água. Em seguida a água isenta de óleos é direcionada para o tanque de 
homogeneização, ajuste de $\mathrm{pH}$ e transparência com agitação por ar, onde são adicionados os reagentes químicos e soluções (ácido, base e floculantes), passando posteriormente pelo filtro misto de areia e carvão ativado para eliminação de possíveis solventes, sendo na seqüência bombeado para o tanque decantador com fundo cônico, para precipitação de metais e sólidos suspensos, direcionando a borra para tambores de descarte e a água tratada para a rede pública, atendendo, conforme CETESB (2017) a legislação ambiental para lançamentos.

Para implantar a $\mathrm{P}+\mathrm{L}$ com o objetivo de reuso do efluente em seu processo produtivo, a empresa complementou o sistema de tratamento para garantir a qualidade da água por meio da instalação de unidades necessárias ao polimento, tais como: sistemas de filtração com membrana, oxidação química e desinfecção, conforme apresentado na figura 3 .

Figura 3 - Fluxograma da Estação de Tratamento de Efluentes para reaproveitamento da água

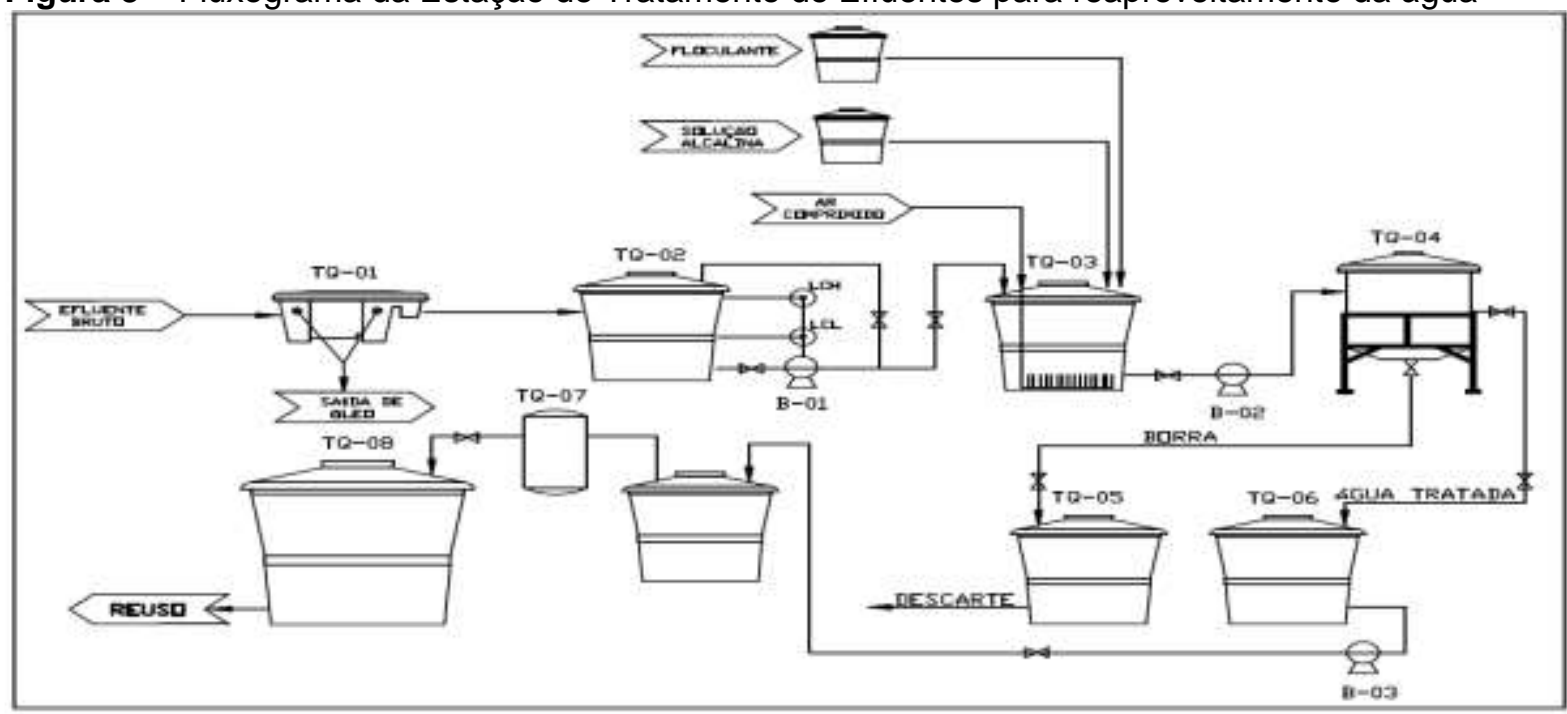

Fonte: Do autor

Para viabilizar o reuso da água tratada em seu processo produtivo, a empresa fez um investimento sua ETE, conforme apresentado na Tabela 1. 


\begin{tabular}{|c|c|}
\hline Item & Investimento \\
\hline Membranas & RS $2.200,00$ \\
\hline Desinfecção & RS 200,00 \\
\hline Filtros & RS 880,00 \\
\hline Bomba & RS $\mathbf{3 0 0 , 0 0}$ \\
\hline Cx. D’água & RS 320,00 \\
\hline Tubulações & RS 160,00 \\
\hline Mão de obra & RS 500,00 \\
\hline
\end{tabular}

Fonte: Do autor

O sistema foi projetado para promover a separação sólido - líquido, por meio da decantação contínua dos precipitadores pelo principio de decantação lamelar, tratando-se de um módulo de tratamento de despejos industriais, com capacidade para atender uma vazão de 5.000 litros/dia, e para viabilizar o reuso da água a empresa investiu $\mathrm{R} \$ 4.560,00$.

Os valores comparativos dos gastos médios mensais para manutenção da ETE, antes e depois das ações de $\mathrm{P}+\mathrm{L}$, são apresentados na Tabela 2:

Conforme apresentado na tabela 2, a empresa tem um gasto médio anual para manter a ETE sem a $P+L$ de $R \$ 122.716,08$, e com a $P+L$ de $R \$ 62.780,08$, e mesmo com o aumento anual de $\mathrm{R} \$ 4.920,00$ nos gastos com produtos químicos, energia e elétrica e análises laboratoriais para o reuso da água, o impacto causado no consumo de água com a $\mathrm{P}+\mathrm{L}$ representou uma redução de aproximadamente $60,7 \%$ no consumo, o que em termos financeiros gerou uma economia anual de $R \$$ $64.856,00$, subtraindo-se o aumento anual de gastos para o reuso da água de $R \$$ $4.920,00$, resulta em um ganho de $R \$ 59.936,00$ no ano para a empresa. 
Tabela 2 - Levantamento econômico

\begin{tabular}{|c|c|c|c|c|}
\hline ITEM & $\begin{array}{c}\text { Gasto anual sem } \\
\qquad+\mathrm{L}\end{array}$ & $\begin{array}{c}\text { Gasto anual com } \\
\qquad+\mathrm{L}\end{array}$ & Resultado anual & Resultado mensal \\
\hline Produto químico & $\mathrm{R} \$ 1.200,00$ & RS $2.640,00$ & $+\mathrm{R} \$ 1.440,00$ & $+\mathrm{R} \$ 120,00$ \\
\hline Cal & $\mathrm{R} \$ 180,00$ & $\mathrm{R} \$ 180,00$ & $\mathrm{R} \$ 0,00$ & RS 0,00 \\
\hline Carvão ativo & $\mathrm{R} \$ 180,00$ & $\mathrm{R} \$ 180,00$ & $\mathrm{R} \$ 0,00$ & RS 0,00 \\
\hline Areia & $\mathrm{R} \$ 600,00$ & RS 600,00 & R\$ 0,00 & RS 0,00 \\
\hline Energia elétrica & R\$ 960,00 & RS $1.440,00$ & $+\mathrm{R} \$ 480,00$ & $+\mathrm{R} \$ 40,00$ \\
\hline Mão de obra & RS $7.200,00$ & RS $7.200,00$ & R\$ 0,00 & $\mathrm{R} S 0,00$ \\
\hline Análises & $\mathrm{R} \$ 1.500,00$ & RS $4.500,00$ & $+\mathrm{R} \$ 3.000,00$ & $+\mathrm{R} \$ 250,00$ \\
\hline Cadris & RS $1.000,08$ & RS $1.000,08$ & $+\mathrm{R} \$ 0,00$ & RS 0,00 \\
\hline Transporte & $\mathrm{R} \$ 600,00$ & $\mathrm{RS} 600,00$ & $\mathrm{R} \$ 0,00$ & $\mathrm{R} S 0,00$ \\
\hline Destinação & RS $2.496,00$ & RS $2.496,00$ & $\mathrm{R} \$ 0,00$ & RS 0,00 \\
\hline Água & $\mathrm{R} \$ 106.800,00$ & R\$ $41.944,00$ & -RS $64.856,00$ & $-\mathrm{R} \$ 5.404,67$ \\
\hline TOTAL & $\mathrm{R} \$ 122.716,08$ & R\$ $62.780,08$ & -RS 59.936,00 & -R\$ 4.994,67 \\
\hline Média mensal & $\mathrm{R} \$ 10.226,34$ & RS 5.231,67 & & \\
\hline Redução total & & & -RS 59.936,00 & $-R \$ 4.994,67$ \\
\hline
\end{tabular}

Fonte: Do autor

Com a aplicação de $\mathrm{P}+\mathrm{L}$ este ganho foi possível por meio da reutilização de águas residuais tratadas para aplicações não potáveis no processo de fabricação. Enquanto o tratamento de águas residuais convencional pretendia atender apenas os padrões de descarga, a motivação da empresa para implantar a $P+L$ foi reduzir os custos pela redução do consumo de água por meio da sua reutilização. A redução do consumo de água foi de aproximadamente $60,7 \%$ ao mês, passando de $360 \mathrm{~m}^{3}$ / mês para 116,28 $\mathrm{m}^{3}$ / mês, o que em termos financeiros gerou uma economia na manutenção da ETE de R $\$ 4.994,67 /$ mês.

Os resultados também permitem visualizar que o retorno do investimento de $\mathrm{R} \$ 4.560,00$ feito pela empresa na ETE, foi em menos de dois meses, tendo em vista que a economia gerada pelas ações foi de $R \$ 4.994,67$ por mês, conforme demonstrado no cálculo do ROI apresentado na Tabela 3. 
Tabela 3 - Cálculo de retorno de investimento na empresa

\begin{tabular}{|c|c|c|c|c|c|c|}
\hline Investimento em Equipamento & 4.560 & & & & & \\
\hline Prazo de depreciação (anos) & 10 & & & & & \\
\hline Depreciação Anual & 456 & & & & & \\
\hline Redução de Custo Anual Obtida & 64.856 & & & & & \\
\hline Depreciação Anual & -456 & & & & & \\
\hline Base para Cálculo do Imposto de Renda (IR) & 64.400 & & & & & \\
\hline IRPJ + CSLL (Cont. Social sobre Lucro) & $30,0 \%$ & & & & & \\
\hline Valor do IR + CSSL Anual & -19.320 & & & & & \\
\hline Redução de Custo Líquida Anual & 45.080 & & & & & \\
\hline Redução de Custo Líquida Anual & 45.080 & & & & & \\
\hline Depreciação Anual & 456 & & & & & \\
\hline Geração de Caixa Anual & 45.536 & & & & & \\
\hline \multicolumn{7}{|l|}{ Fluxo de } \\
\hline Investimento & -4.560 & & & & & \\
\hline Geração de Caixa Anual & & 45.536 & 45.536 & 45.536 & 45.536 & 45.536 \\
\hline Fluxo de Caixa Total & -4.560 & 45.536 & 45.536 & 45.536 & 45.536 & 45.536 \\
\hline ROI ou TIR & $998,6 \%$ & /ano & & & & \\
\hline Payback Descontado a $15 \%$ ao ano & 0,15 & anos & & & & \\
\hline
\end{tabular}

Fonte: Do autor

Em relação aos benefícios ambientais, pode-se observar a significativa redução do consumo de água e o impacto ambiental que essa redução proporciona ao meio ambiente.

\section{DISCUSÃO}

Tratar de forma eficiente os efluentes gerados tornou-se imprescindível ao setor industrial, e a $\mathrm{P}+\mathrm{L}$ tem potencial para melhorar significativamente 0 desempenho ambiental e econômico das indústrias, possibilitando proteção ao meio ambiente. O reuso das águas do processo de fabricação torna-se fundamental à realidade das indústrias, possibilitando a diminuição dos custos gerais, como ficou demonstrado neste estudo, onde, com um investimento de $R \$ 4.560,00$ a empresa alcançou uma redução nos gastos de manutenção mensal de $R \$ 10.226,34$ para $R \$$ 5.231,67 em sua ETE, pelo reuso da água, ou seja, uma redução de 48,84\%, gerando uma economia de $\mathrm{R} \$ 4.996,67$ por mês.

O reuso de efluentes tratados para fins não potáveis, tem sido cada vez mais aceito e sua viabilidade tem sido comprovada (MITCHELL, 2006). A água de reuso 
pode ser utilizada para inúmeras finalidades, como geração de energia, refrigeração de equipamentos, aproveitamento nos processos industriais entre outros. O tratamento de efluente convencional conforme Harceag (2005) tem o objetivo de atender aos padrões de lançamento para seu descarte. A principal motivação para que as empresas promovam o seu reuso nos processos de fabricação, é a redução de custos (SEIFFERT, 2008; GIANNETTI et al., 2008).

Fatores econômicos e financeiros são entendidos pelas PEs metal mecânicas como barreiras de difícil superação, pois, estão relacionadas com investimentos em novas tecnologias, sendo considerados por algumas empresas como investimento não rentável (ILOMAKI; MELANEN, 2001; RADONJIC; TOMINC, 2007). Para Siaminwe et al., (2005) a falta de investimentos em novas tecnologias resulta em despejo de efluentes contaminados prejudicando o meio ambiente, e para Vieira e Amaral, (2016) no caso das PEs metal mecânicas, além da falta de recursos financeiros há também falta de recursos humanos preparados, o que dificulta ações voltadas ao meio ambiente, reforçando o que afirma Corral, (2003) quando relata que dois determinantes explicam a incerteza na disposição das empresas de investir em tecnologias mais limpas, sendo eles, a capacidade tecnológica e o risco econômico percebido. As PEs possuem baixa capacidade tecnológica e pouco acesso às informações sobre tecnologias limpas, e acabam fazendo uso de tecnologias obsoletas além de ter pouco controle sobre seus processos (HITCHENS et al., 2004; VAN HOOF; LYON, 2013).

A redução de custos é para as indústrias um dos mais importantes resultados da implantação da $\mathrm{P}+\mathrm{L}$, pois ela estabelece poderosas estratégias gerando lucros através da minimização de resíduos e redução no consumo de matérias prima, água e energia, conseqüentemente, poupando a natureza e preservando o meio ambiente.

\section{CONCLUSÃO}

A P $+\mathrm{L}$ para as PEs do setor metal mecânico é algo ainda desconhecido, pois, predomina no setor a crença de que práticas direcionadas à preservação ambiental acarretam aumento de custos e perda de competitividade, e que investimentos direcionados à preservação do meio ambiente não gera retorno econômico. Neste 
estudo podemos observamos resultados positivos das ações tomadas pela empresa na implantação da $\mathrm{P}+\mathrm{L}$ em sua ETE, demonstrando que é possível obter ganho econômico com ações direcionadas à preservação do meio ambiente, com um ganho anual para a empresa de $\mathrm{R} \$ 59.936,00$, respondendo desta maneira a primeira pergunta de pesquisa, demonstrando que o ganho econômico permite que as empresas do setor metal mecânico adotem ações de $P+L$ em seus processos produtivos.

Embora a implantação de ações de $\mathrm{P}+\mathrm{L}$ requeira algum investimento inicial, a empresa pode lucrar obtendo o retorno desse investimento em curto prazo de tempo, conforme demonstrado nesse estudo, por meio do cálculo do retorno do investimento ROI, onde, com um investimento de $\mathrm{R} \$ 4.560,00$ a empresa obteve uma economia de $\mathrm{R} \$ 4.994,67$ por mês, promovendo o retorno do investimento em menos de dois meses, respondendo assim a segunda pergunta de pesquisa, demonstrando que a identificação do tempo de retorno do investimento por meio do calculo ROI motiva as PEs a adotarem a P+L.

O resultado deste trabalho tem grande importância para as indústrias metal mecânica, pois ela necessita de informações sobre a possibilidade de obter ganhos econômicos com a melhoria da qualidade ambiental dos seus produtos e processos de fabricação, e colabora também com a literatura, apresentando um caminho de forma prática e viável para a implantação da $\mathrm{P}+\mathrm{L}$ pelas empresas.

Este estudo se limitou a avaliar os resultados econômicos da aplicação da $\mathrm{P}+\mathrm{L}$ na ETE de uma empresa do segmento metal mecânico, demonstrando pelos resultados obtidos a importância de novas pesquisas sobre o assunto em outros segmentos, avaliando os resultados econômicos e também os resultados ambientais das ações.

\section{REFERÊNCIAS}

ABDULRAHMAN, A.O., HUISINGH, D., HAFKAMP, W. Sustainability improvements in Egypt's oil \& gas industry by implementation of flare gas recovery, Journal Cleaner Production, v. 98, pp. 116 - 122, 2015. DOI: https://doi.org/10.1016/i.jclepro.2014.11.086

ALMEIDA, C.M.V.B.; AGOSTINH, F.; GIANNETTI, B.F.; HUISINGH, D. Integrating cleaner production into sustainability strategies: an introduction to this special volume. Journal of

Cleaner Production, v. 96, pp. 1 - 9, 2015. DOI: https://doi.org/10.1016/j.jclepro.2014.11.083

BAAS, L.To make zero emissions technologies and strategies become a reality, the lessons 
learned of cleaner production dissemination have to be known. Journal Cleaner

Production, V.15, pp.1205 -1216, 2007. DOI: https://doi.org/10.1016/j.jclepro.2006.07.017

BALESTRIN, A., VARGAS, L.M., Dimensão estrategica das redes horizontais de PMEs: Teorizações e Evidências. Revista de Administração Contemporânea, pp. 203 - 227. Edição Especial, 2004.

BOGDAN, R.; BIKLEN, S. Qualitative research for education: an Introduction to Theory and Method, 2. ed., Boston: Allyn and Bacon, 1992, 276 p.

BRYMAN, A. Research methods and organization studies. London: Routledge, 1995, 304 p.

CAMARGOS, M.A., CAMARGOS, M.C.S., SILVA, F.W.S., SANTOS, F.S., RODRIGUES, P.J., Fatores condicionantes de inadimplência em processos de concessão de credito a micro e pequenas empresas do Estado de Minas Gerais. Revista Administração Contemporanea, n.14, v. 2, pp. 333 - 352, 2010. DOI: https://doi.org/10.1590/S1415$\underline{65552010000200009}$

CETESB - Companhia de Tecnologia de Saneamento Básico. Produção mais limpa. Disponível em: http://www.cetesb.sp.gov.br. Acesso em: 26 ago. 2017.

CLEMENS, B. Economic incentives and small firms: does it pay to be green? Journalof Business Research, v. 59, n.4, pp. 492-500, 2006. DOI: https://doi.org/10.1016/j.jbusres.2005.08.006

CNTL - CENTRO NACIONAL DE TECNOLOGIAS LIMPAS. Meio ambiente e a pequena e microempresa: módulo 1 - Curso de Formação de Consultores em Produção Mais Limpa. Porto Alegre: p. 73, 2003.

CNTL. Centro Nacional de Tecnologias Limpas. Serviço Nacional de Aprendizagem Industrial (SENAI), Disponível em: http://www.senairs.org.br/Cntl/. Acesso 01 de out. 2017.

COLLINS, J.; HUSSEY, R. Business research methods. $2^{\underline{a}}$ ed., New York: McGraw-Hill., 2007, $764 \mathrm{p}$.

CORRAL, C.M. Sustainable production and consumption systems cooperation for change: assessing and simulating the willingness of the firm to adopt/develop cleaner technologies. The case of the In-Bond industry in northern Mexico, Journal of Cleaner Production, v. 11, pp.411 - 426, 2003. DOI: https://doi.org/10.1016/S0959-6526(02)00063-X

DAQUINO, S.F., PRA, F.D.B., GOULART, M.C., CAMPOS, L.M., MIGUEL, P.A.C., Uma analise da aplicação empírica da produção mais limpa na manufatura. Journal of Cleaner Production, n.11, v. 3, pp. 246 - 258, 2014.

DELOITTE, D. T. T. L. A receita da rentabilidade para expandir os negócios: Um estudo sobre as PMEs que mais crescem no Brasil. São Paulo: Deloitte, 2011.

DUARTE, P. D.; VENTURA, F.; ROCHA, C.; CATARINO, J.; FRAZÃO, R.; FERNANDES, R.; MAIA, A.; TRINDADE, P.; LANÇA, A.; PENEDA, C. Sustainable Production Programme in Setúbal Region (PROSSET) final results. Journal of Cleaner Production, v. 13, n. 4, pp. 363-372, 2005. DOI: https://doi.org/10.1016/j.jclepro.2003.10.006

EDER, P., Expert inquiry on innovation options for cleaner production in the chemical 
industry, Journal of Cleaner Production, n.11, v. 4, 347 - 364, 2003. DOI: https://doi.org/10.1016/S0959-6526(02)00060-4

EISENHARDT, K. M. Building theories from case study research. Academy of Management Review.Mississippi State, Academy of Management, v.14, n.4, p. 532-550, 1989.

GAJDZIK,B.Environmental aspects, strategies and waste logistic system based on the example of metalurgija, Metabk, n. 1,v. 48, pp. 63 - 67, 2009.

GIANNETTI, B.F. ALMEIDA, C.M.B.V. Ecologia Industrial: Conceitos, ferramentas e aplicações. São Paulo, Editora Edgard Blücher, 2006. DOI:

https://doi.org/10.1016/j.jclepro.2007.06.002

GIANNETTI, B. F.; BONILLA, S. H.; SILVA, I. R.; ALMEIDA, C. M. V. B. Cleaner production practices in a medium size gold-plated jewelry company in Brazil: when little changes make the difference. Journal of Cleaner Production, n. 10, v. 16, pp. 1106-1117, 2008.

GONÇALVES, G.M.S., PESSOA, E., MOREIRA, M.F., Causas de falências de micro e pequenas empresas nos primeiros anos de atividade: um estudo exploratório. In:

Proceedings of 18 Encontro Anual da Associação de Cursos de Graduação em Administração, Cuiaba, MT, Brasil, 2007.

HALILA, F. Networks as a means of supporting the adoption of organizational innovations in SMEs: the case of environmental management systems (EMSs) based on ISO 14001.

Corporate Social Responsibility and Environmental Management, n.3, v.14, pp. 167181, 2007. DOI: https://doi.org/10.1002/csr.127

HARCEAG, V. Water pollution prevention actions in Romanian industry. Modern Tools and Methods of Water Treatment for Improving Living Standards NATO Science Series: IV Earth and Environmental Sciences, v.48, pp. 315 - 323, 2005. DOI: https://doi.org/10.1007/1-4020$\underline{3116-5 \quad 25}$

HICKS, C.; DIETMAR, R. Improving cleaner production through the application of environmental management tools in China, Journal Cleaner Production, v. 15, pp. 395 408, 2007. DOI: https://doi.org/10.1016/.j.jclepro.2005.11.008

HITCHENS, D.; CLAUSEN, J.; TRAINOR, M.; KEIL, M.; THANKAPPAN, S. Competitiveness, Environmental Performance and Management of SMEs, Greenleaf Publishing, pp. 45 - 57, 2004.

HOFFMAN, A.J. From Heresy to Dogma: an Institutional History of Corporate Environmentalism, New Lexington Press. Stanford Business Books, San Francisco California, 2001.

ILOMAKI, M.; MELANEN, M. Waste minimisation in small and medium-sized enterprises do - environmental management systems help? Journal of Cleaner Production, v.9, n. 3, pp. 209 - 217, 2001. DOI: https://doi.org/10.1016/S0959-6526(00)00053-6

JABBOUR, C.J.C. Non-linear path ways of corporate environmental management: a survey of ISO 14001-certified companies in Brazil. Journal of Cleaner Production, v.18, pp. 1222 - 1225, 2010. DOI: https://doi.org/10.1016/ij.jclepro.2010.03.012

KLEWITZ, J.; HANSEN, E.G. Sustainability-oriented innovation of SMEs: a systematic 
review, Journal of Cleaner Production, v. 65, pp. 57 - 75, 2014. DOI:

https://doi.org/10.1016/i.jclepro.2013.07.017

KLIOPOVA, I., STANISKIS, J.K.. The evaluation of cleaner production performancein Lithuanian industries. Journal Cleaner Production, v. 14, pp. 1561 - 1575, 2006. DOI: https://doi.org/10.1016/j.jclepro.2005.04.017

LOPES SILVA, D. A.; DELAI, I.; SOARES DE CASTRO, M. A.; OMETTO, A. R. Quality tools applied to Cleaner Production programs: a first approach toward a new methodology. Journal of Cleaner Production, v. 47, pp.174 - 187, 2013. DOI:

https://doi.org/10.1016/j.jclepro.2012.10.026

MARCONI, M. A., LAKATOS, E. M. Fundamentos de metodologia científica. 3. ed, São Paulo: Atlas, 2005.

MEDEIRO, D.D.; CALABRIA, F.A; SILVA,G.C.S.; FILHO, J.C.G. Aplicação da produção mais limpa em uma empresa como ferramenta de melhoria contínua. Revista Produção, v. 17, pp.109-128, 2007.

MITICHELL, C.L., Beyond barriers: examining root causes behind commonly cited Cleaner Production barriers in Vietnam. Journal of Cleaner Production, v.14, pp. 1576 - 1585, 2006. DOI: https://doi.org/10.1016/i.jclepro.2005.04.010

MOORS, E.H.M.; MULDER, K.F.; VERGRAGT, P.J.; Towards cleaner production: barriers and strategies in the base metals producing industry. Journal of Cleaner Production, $v$. 13, pp. 657 - 668, 2005. DOI: https://doi.org/10.1016/j.jclepro.2003.12.010

OURA, M.M.; SOUSA, T.S.; A evolução das tacnologias end-of-pipe às Tecnologias Limpas em indústrias de torrefação de café. ENERGEP - Foz do Iguaçú, PR, Brasil, 09 a 11 de Outubro de 2007.

OLIVEIRA, J.F.G.; ALVES, S.M. Adequação ambiental dos processos usinagem utilizando Produção mais Limpa como estratégia de gestão ambiental, Produção, v. 17, n. 1, pp. 129 38, 2007. DOI: https://doi.org/10.1590/S0103-65132007000100009

PETROESC, V.; MORARU, R. I. Industrial pollution and control measures in Romanian foundries: Annals of Faculty Engineering Hunedoara. International Journal of Engineering, extra facicule, 2011.

PNUMA, Programa das Nações Unidas para o Meio Ambiente, Disponível em http://www.brasilpnuma.org/pordentro/artigos 019.htm. Acesso 18 de out. 2017.

RADONJIC, G.; TOMINC, P. The role of environmental management system on introduction of new technologies in the metal and chemical/paper/plastics industries. Journal of Cleaner Production, v. 15, n. 15, pp.1482 - 1493, 2007.DOI:

https://doi.org/10.1016/j.jclepro.2006.03.010

RADOVIC, N.; KAMBEROVIC, Z.; PANIAS, D. Cleaner Metallurgical Industry in Serbia: A road to the Sustainable Development. Chemical Industry \& Chemical Engineering Quarterly, v. 15, n.1, pp. 1 - 4, 2009. DOI: https://doi.org/10.2298/CICEQ0901001R

ROSENBLOOM, S. Sustainability and automobility among the elderly an international assessment. Transportation, v. 28, n.4, pp. $375-408$, 2001. DOI:

https://doi.org/10.1023/A:1011802707259 
SANTOS, R. N. M; KPOBASHI, N. Y. Bibliometria, Cientometria, Infométrica, conceitos e aplicações. Pesquisa Brasileira de Comunicação e Informação, Brasilia, v.2, n.1, pp.155 172, 2009.

SEBRAE, Serviço Brasileiro de Apoio às Micro e Pequenas Empresas, Boletim Estatístico de Micro e Pequenas Empresas, Observatório do SEBRAE, Brasília, Primeiro Semestre, 2005.

SEBRAE. Serviço Brasileiro de Apoio às Micro e Pequenas Empresas, Anuário do Trabalho 2012 na Micro e Pequena Empresa; Disponível em: http://www.sebrae.com.br/Sebrae/Portal\%20Sebrae/Anexos/Anuario\%20do\%20Trabalho\%2 0Na\%20Micro\%20e\%20Pequena\%20Empresa 2012.pdf. Acesso em: 15 ago. 2017

SEIFFERT, M.E.B. Environmental impact evaluation using a cooperative model for implementing EMS (ISO 14001) in small and medium-sized enterprises. Journal of Cleaner Production, v.16, pp.1447 - 1461, 2008. DOI: https://doi.org/10.1016/j.jclepro.2007.10.001

SEVERO, E.A.; GUIMARÃES, J.C.F.; DORION, E.C.H.; NODARI, C.H. Cleaner production, environmental sustainability and organizational performance: na empirical study in the Brazilian Metal-Mechanic, Journal of Cleaner Production, v. 96, pp. 118 - 125, 2015. DOI: https://doi.org/10.1016/i.jclepro.2014.06.027

SEVERO, E.A.; OLEA, P.M.Metodologias de Produção mais Limpa: Um Estudo de Caso no Pólo Metal-Mecânico da Serra Gaúcha, INGEPRO - Inovação, Gestão e Produção, v.2, n. 6, pp. $73-81,2010$.

SHI, H.; PENG, S. Z.; LIU, Y.; ZHONG, P. Barriers to the implementation of cleaner production in Chinese SMEs: government, industry and expert stakeholders' perspectives. Journal of Cleaner Production, v. 16, n. 7, pp. 842-852, 2008. DOI:

https://doi.org/10.1016/j.jclepro.2007.05.002

SIAMINNWE, L.; CHISEMBU, K. C. SYAKALIMA, M. Policy and operational constraints for the implementation of cleaner production in Zambia. Journal of Cleaner Production, v.13, n.10, pp. 1037-1047, 2005. DOI: https://doi.org/10.1016/j.jclepro.2004.12.005

SILVA, A.L.E.; MORALES, J.A.R.; MACHADO, E.L. Proposta de produção mais limpa voltada às práticas de ecodesign e logística reversa, Engenharia Sanitaria e Ambiental, v. 20,n.1, p. 29-37, 2015. DOI: https://doi.org/10.1590/S1413-41522015020000087843

SILVESTRE, B.S., SILVA NETO, R. Are cleaner production innovations the solution for small mining operations in poor regions? The case of Padua in Brazil. Journal of Cleaner Production. v.84, pp. $809-817,2014$. DOI:

https://doi.org/10.1016/j.jclepro.2014.01.097

SISSINO, C.L.S.; MOREIRA, J.C. Ecoeficiência: um instrumento para a redução da geração de resíduos e desperdícios em estabelecimentos de saúde, Caderno Saúde Pública, Rio de Janeiro, v. 21, n.6, pp. 1893 - 1900, 2005.

STUDER, S.; WELFORD, R.; HILLS, P. Engaging Hong Kong business in environmental change: drivers and barriers. Business Strategy and the Environment, v. 15, n.6, pp. 416 431, 2006. DOI: https://doi.org/10.1002/bse.516 
UNEP, Cleaner production energy efficiency e manual. Oxford: United Nations Publication, 2004.

UNIDO. Cleaner production toolkit. Introduction into cleaner production. v.1, 2002.

UNIDO/UNEP. Manual on the Development of Cleaner Production Policies Approaches and Instruments. 2002. Disponível em :http://www.unido.org/fileadmin/import/9750 0256406e.pdf, Acesso, 10 de Ago de 2017.

VALLE CE Qualidade ambiental: como ser competitivo protegendo o meio ambiente, v.2. Pioneira, São Paulo, 1995.

VAN BERKEL. A profitable road for sustainable development of Australian industry. Clean Air, v. 33, n. 4, pp. 33 - 38, 2000. DOI: https://doi.org/10.1016/S0959-6526(97)00005-X

VAN BERKEL, R.; Cleaner production and eco-efficiency initiatives in Western Australia 1996 e 2004, Journal of Cleaner Production, v. 15, n. 8 - 9, pp. 741 - 755, 2007.

VAN BERKEL, R.; WILLEMS, E.; LAFLEUR, M. Development of an industrial ecology toolbox for the introduction of industrial ecology in enterprises. Journal of Cleaner Production, v.5, n. 1-2, pp. 11-25, 1997.

VAN HOOF, B.; LYON, T. P. Cleaner production in small firms taking part in Mexico's Sustainable Supplier Program, Journal of Cleaner Production, v. 41, pp.270 - 282, 2013. DOI: https://doi.org/10.1016/i.jclepro.2012.09.023

VIEIRA, L.C.; e AMARAL, F.G. Barriers and strategies applying Cleaner Production: a systematic review, Journal of Cleaner Production, v. 113, pp. 5 - 16, 2016. DOI: https://doi.org/10.1016/j.jclepro.2015.11.034

YIN, R. K. Estudo de caso: planejamento e métodos. 5ํe. São Paulo: Ed. Bookman, 320 pp., 2015.

WORTHINGTON, I.; PATTON, D. Strategic intent in the management of the Green environment within SMEs, Long Range Planning, v.38, n.2, pp. 197 - 212, 2005. DOI: https://doi.org/10.1016/j.Irp.2005.01.001

ZHANG, T.Z. Policy mechanisms to promote cleaner production in China. Journal Environmental Science, Health A Toxic Hazard. Subst. Environmental Eng. v.35, 2000.

ZHANG, B.; BI, J.; LIU, B. Drivers and barriers to engage enterprises in environmental management initiatives in Suzhou Industrial Park, China, Front. Environ. Sciece Enginering, v. 3, n. 2, pp. 210 - 220, 2009. DOI: https://doi.org/10.1007/s11783-009-0014-7

ZHANG, B.; YANG, S.; BI, J. Enterprises' willingness to adopt/develop cleaner production technologies: an empirical study in Changshu, China, Journal of Cleaner Production, v. 40, pp. 62 - 70, 2013. DOI: https://doi.org/10.1016/j.jclepro.2010.12.009

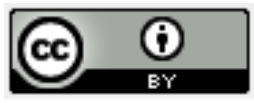

Artigo recebido em: 24/11/2017 e aceito para publicação em: 06/11/2018 DOI: http://dx.doi.org/10.14488/1676-1901.v18i4.3076 